\title{
Vulnerability in the neighbourhood: A study of gender differences in perceptions of control
}

\author{
Chloe Keel \\ Monash University, School of Social Science \\ chloe.keel@monash.edu \\ Rebecca Wickes \\ Monash University, School of Social Science \\ Murray Lee \\ University of Sydney, Sydney Law School \\ Jonathan Jackson \\ London School of Economics, Department of Methodology \\ Kathryn Benier \\ Monash University, School of Social Science
}

\section{Journal article pre print}

This is the version of this article submitted to a journal for publication. It has not yet been peer reviewed. It may vary from the final published version.

\section{Abstract}

Women perceive themselves as more vulnerable to crime than men, and report greater sensitivity to risk in their environmental context. This heightened sense of vulnerability is associated with women's perceptions of control over victimisation. Yet, the specific features of neighbourhoods that foster perceptions of control are not well understood. Drawing upon administrative data and a survey of 80 neighbourhoods and 2,862 participants in Victoria, Australia, we test whether gendered neighbourhoodlevel inequalities or broader neighbourhood characteristics are associated with lower perceived control over victimisation for women. Results indicate that gendered neighbourhood inequalities are less important for women's perceptions of control compared to men. However, women's perceptions of control are lower than men's in neighbourhoods with lower collective efficacy and higher disadvantage.

\section{Keywords}

Victimology; neighbourhoods; women; control over potential victimisation; vulnerability 


\section{Introduction}

Women are significantly less likely than men to perceive control over their victimisation (Killias 1990; Jackson 2009). This has been largely attributed to their own sense of vulnerability (Hale 1996; Warr 1984; Killias 1990), which is a function of their subordinate social, economic and political status, and their experience of harassment and violence in the public realm (Stanko 1990; Pain 2001; Fileborn 2019). While it is well established in criminological scholarship that women report higher levels of worry and fear about victimisation compared to men, less attention has been paid to the dynamics of vulnerability, which may be important to understanding why this is the case (Franklin and Franklin 2009; Fisher and May 2009; Snedker 2015).

Women's lives are influenced by structural inequalities and collective experiences that manifest in both private and public spaces (Fileborn 2019; Pain 2001; 2000; 1997; Stanko 1995). There is extensive research on women's experience of control and violence in the private realm, yet women's sense of control in the public realm is less well understood (Stanko 1990). In public space, women's perceived control is tied to assessments of threat and danger in part through the conditions of the environment and the behaviours of others in that environment (Tulloch and Jennett 2001; Cobbina et al. 2008). Unequal and gendered power relationships that shape micro-experiences of control (Walklate 1997; Stanko 1997; Walklate 2017) may also exist at larger units of scale, such as the neighbourhood.

Simone de Beauvoir's (1949) account of women's treatment throughout history concludes that the key to female empowerment is women's economic independence. Blumberg (1984) expands on de Beauvoir's idea. Where de Beauvoir looks primarily at individual experience, Blumberg looks beyond individual experience to question how women's experiences are shaped not only by their own economic power but also by the economic power of other women in their community. Studies have demonstrated that the ecological context is important for perceptions of crime and that the features of the neighbourhood have distinct effects (Brunton-Smith and Sturgis 2011; Brunton-Smith, Jackson, and Sutherland 2014), but whether collective processes and neighbourhood features are gendered and, further, whether they lead to greater or lesser control is unclear.

This paper focuses on particular neighbourhood gendered inequalities and their links to women's and men's sense of control over their victimisation. We begin with an overview of the proposed theoretical framing to understand individual perceptions of control as they relate to individual vulnerability, and the key neighbourhood features that drive these perceptions. We argue that structural inequalities between women and men generate distinct neighbourhood stimuli linked to control over one's victimisation. To test this proposition, we analyse cross-sectional survey data from the $\mathrm{XXXXXXX}$ project, as well as administrative data. Using multilevel models with cross-level interactions, we assess how individual perceptions of control are related to neighbourhood dynamics. We finish the paper with a discussion of the implications of our findings to scholarship on vulnerability and neighbourhoods. 


\section{Vulnerability and perceived controllability of victimisation}

In studies drawn from victimology, individuals' concerns about crime are largely understood through vulnerability frameworks. Traditionally, vulnerability was conceptualised as an increased risk for particular social groups with a higher likelihood of being a victim of crime (Hale 1996; Warr 1984; 1987). This approach has been popular in explaining differences in fear of crime for women and men. Killias' (1990) vulnerability thesis proposes that women's heightened worry is due to their increased vulnerability to physical, social and situational risks. Vulnerability has three factors-exposure to risk, loss of control or lack of effective protective mechanisms, and anticipation of serious consequences. When one's perceived risk is high and perceived ability to protect oneself is low, there is an increased anticipation of serious consequences from victimisation. This in turn triggers an individual's worry and fear of crime. From this perspective, women are viewed as unable to protect themselves from particular types of criminal behaviour from men, making them more vulnerable to victimisation (Killias and Clerici 2000; Killias 1990).

Early criminological works (Warr 1984; 1987; Killias 1990) were foundational to the theorisation and conceptualisation of gender differences in fear of crime studies. Yet in the following two decades of scholarship, being female became a proxy variable for vulnerability - drawing considerable criticism (Stanko 1997; Lee 2007; Walklate 2017). A more refined social psychological model of vulnerability (Jackson 2009; 2011) suggests that three factors define an individual's perceived vulnerability to victimisation: perceived heightened likelihood of victimisation, perceived low control, and intensified sense of the consequences of victimisation. Jackson (2009) found that women worried more frequently about personal crime in public space than men, and that this was largely explained by lower feelings of control and higher perceptions of likelihood and consequence. Self-related physical ability to defend oneself was strongly correlated with perceived control for men and women. However, the fact that perceived control was only a predictor of worry among women suggests that controllability is gendered when it comes to fear of crime.

Control over potential victimisation refers to an individual's belief that they can resist crime physically, avoid crime situationally and/or draw on social protective mechanisms to prevent or reduce crime victimisation (Killias 1990; Fisher and Naser 1992; 1995; Jackson 2011). Protective mechanisms can include a sense of power over one's environment, in part determined by one's social position (Jackson 2011; Tulloch 2003). For example, Tulloch (2003) found that both female and male participants who felt powerless lived in environments where the actions of others were viewed as "uncontrollable" (Tulloch 2003, 475). The combination of powerlessness to prevent victimisation and the belief that one cannot protect themselves if they were to be victimised leads to a perceived loss of control.

Until recently, much of the fear of crime literature has characterised women's lack of control over their victimisation as linked to their inherent vulnerability, understood through stereotypes of physical strength and the threat of sexual violence (Killias and Clerici 2000). This perspective proposes 
that women's heightened risk and lowered control is a function of the shadow of sexual assault, in which women's fear, risk and control can be explained through the threat of rape and weakened physical ability to fight off an attacker (Ferraro 1996). However, this assertion is not always supported by empirical research (Reid and Konrad 2004; Hirtenlehner and Farrall 2014; Riggs and Cook 2015). More recently, research suggests that the prevalence of sexual assault and worry about sexual assault does not fully explain women's fear of crime (Hirtenlehner and Farrall 2014). Rather, risks that are particular to women, such as sexual violence, are a manifestation of broader social inequalities between women and men.

Stanko (1990) outlined long ago that the study of women's perceived control must encapsulate the lived dynamics that reinforce inequalities between women and men. Such lived dynamics are derived from cues in the environment and understandings of community life through which they can determine the predictability of residents' behaviour (Fisher and May 2009; May 2001; Cobbina et al. 2008). This is reinforced by research that points to the connection between vulnerability, control and an environmental backcloth differentially experienced by women and men (Franklin and Franklin 2009). Thus, while social inequalities between women and men are created at the macro social level, inequalities play out experientially in places where people live and work. In response to predatory male behaviours, such as public harassment (Stanko 1997; Cobbina et al. 2008; Fileborn 2019), women significantly alter their behaviour to avoid risk in public places (Stanko 1997; Cobbina et al. 2008; Fileborn 2019). On the other hand, Koskela's (1997) work demonstrates the ways in which women take control of public space through boldly reclaiming the public realm. Gendered assessments of control can, therefore, be understood through differential environmental contexts which can engender a sense of control or uncontrollability.

Women's assessment of the environmental context are derived through cues and perceptions that play out in neighbourhoods (Snedker 2015), which are gendered. For example, Cobbina and colleagues (2008) found young women derive a sense of safety through the expectation that young men in their community take on the role of defender and protect them from external threats in the neighbourhood. In this way, women perceive their environment, in part, through men's actions and social expectation of men's behaviour in particular places. While considerable scholarship examines the individual-level processes that shape worry and risk perceptions for women and men (Stanko 1997; Cobbina et al. 2008; Snedker 2015), a greater focus on the neighbourhood contexts that may also drive these social processes is needed.

\section{The neighbourhood context and perceptions of control}

Perceptions of crime, and indeed feelings of fear and/or safety, vary across neighbourhoods (BruntonSmith and Sturgis 2011; Brunton-Smith, Jackson, and Sutherland 2014; Pantazis 2000; Sampson, Raudenbush, and Earls 1997). The characteristics of an area, such as crime rates, concentrated poverty and disorderly places, strongly predict individuals' reports of fear (Brunton-Smith and Sturgis 2011; 
Brunton-Smith, Jackson, and Sutherland 2014; Pantazis 2000). Evidence suggests that the magnitude of this relationship differs for women and men (Brunton-Smith and Sturgis 2011; Snedker 2015). Worry about crime is intensified for women living in neighbourhoods with larger populations of young people and greater socioeconomic disadvantage when compared to men (Brunton-Smith and Sturgis 2011).

Collective efficacy, broadly defined as the ability of communities to work together to collectively solve problems, has also been linked to lower fear of crime (Sampson, Raudenbush, and Earls 1997; Brunton-Smith and Sturgis 2011). Those who perceive their community as efficacious report lower levels of fear and/or worry than those who feel their community is unable or unwilling to respond to crime (Brunton-Smith and Sturgis 2011). For individuals vulnerable to crime, the community's perceived capacity to prevent problems is particularly important in reducing fear (Brunton-Smith and Sturgis 2011). Collectively efficacious communities may reduce fear through empowering residents, thereby increasing perceived control.

Gendered neighbourhood dynamics could differentially influence women's and men's perception of control over their victimisation. Preconditions for women's control more broadly are exercised through the gendered stratification of work and the sexual division of labour which can occur in the neighbourhood (Blumberg 1984). Blumberg (1984) argues gendered stratification at the community level is explicitly tied to women's individual level of control over lives. Women tend to partake in higher levels of unpaid family labour which can result in female exclusion from the paid workforce (Baxter, Hewitt and Western 2005). As a result, male dominated public places may be created and reinforced in contexts where women are economically excluded and positioned in the home (Miller 2008). It has been suggested that the gendered stratification of work and sexual division of labour creates conditions stronger social ties among women (Greenbaum and Greenbaum 1985). Although female social ties have the potential to create informal social control in neighbourhoods and control crime, they are less effective in neighbourhoods with high concentrations of female-headed households (Rountree and Warner 1999). Further to this, the spectre and spectrum of gendered violence shapes the everyday realities of women and may, in part, drive assessments of their ability to control victimisation (Jackson 2016; Walklate 2017). Victimisation against women in the public realm clusters within particular neighbourhoods, creating an ecological concentrations of vulnerability for women.

To date only a one prior study has incorporated gendered neighbourhood dynamics in the study of crime perceptions and fear of crime. This scholarship reveals the importance of considering the broader social structural mechanisms that play out in neighbourhoods (Jackson, Soller, and Browning 2017). Jackson and colleagues (2017) found that sex differences in perceptions of neighbourhood problems are mediated in contexts where women have more equal access to resources. For example, when considering women's economic resources relative to males within the neighbourhood, Jackson and colleagues found that women who lived in neighbourhoods with greater socioeconomic equality between the women and men reported fewer neighbourhood problems than their female counterparts living in neighbourhoods with more inequality. Thus, the gendered dynamics of the neighbourhood, in 
particular equal access to socioeconomic resources/power, the sexual division of labour and women's likelihood of victimisation may be particularly important for women's sense of control when compared to men.

\section{Current research}

As discussed, studies suggest that neighbourhoods vary in rates of crime, disadvantage and level of collective efficacy and this variability influences the way people perceive crime and understand risk (Brunton-Smith and Sturgis 2011; Brunton-Smith, Jackson, and Sutherland 2014; Pantazis 2000). These neighbourhood conditions differentially impact women and men. Yet gendered neighbourhood dynamics such as differential economic power for women, women's victimisation rates, and an overreliance on women for family labour, may also influence the way in which women perceive their control (Jackson, Soller, and Browning 2017; Jackson 2016; Soller and Jackson 2018). This study examines these gendered neighbourhood conditions and their association with individual vulnerability for women and men. Two key questions drive this research:

RQ1: How important are broader community processes and characteristics of the neighbourhood (e.g. collective efficacy and disadvantage) for perceptions of control and do these relationships differ for women and men?

RQ2: How important are gendered neighbourhood dynamics (e.g. women's absolute access to resources, women's family labour, women's neighbourhood victimisation rates) for women's perceptions of control?

This study draws upon survey data from the previously cited XXXXXXX project (XXXX 2020). The XXXXXXX examines the individual and neighbourhood context of fear of crime and the activities individuals take in response to fear.

\section{Data and analytical approach}

The XXXXXXX survey data comprises a random sample of 2,862 residents in Victoria, Australia living within 80 random suburbs (70 urban and 10 regional). ${ }^{1}$ Metropolis Research was contracted to conduct face-to-face interviews with participants at randomly selected households within the research suburbs. Interviews lasted between 15 and 25 minutes each.

\footnotetext{
${ }^{1}$ The suburbs were chosen using crime rate as the strata. Crime incident rates were calculated for the year of 2016. Levels of crime were grouped and the crime rate groupings are as follows: $1=$ Low crime $(1$ or more standard deviation below the mean for that year); $2=$ Average crime (within 1 standard deviation of the mean for that year); $3=$ High crime ( 1 or more standard deviations above the mean). To determine how many residents were required per suburb we followed the sampling process from Australian Community Capacity Study (https://accs.project.uq.edu.au/) and Raudenbush and Sampson's (1999) theory of econometrics.
} 
We also integrated Australian Bureau of Statistics (ABS) 2016 Census Data, and crime incident data supplied by the Crime Statistics Agency, Victoria (CSA) with the survey data. In line with previous neighbourhood research, we use State Suburb Codes (SSC) to determine administrative boundaries to from the 2016 Australian Statistical Geography Standard (ASGS). While relying on administrative boundaries is an imperfect measure of 'community', it allows us to capture context of the neighbourhood through both social processes and characteristics of place to understand how these intersect with individual residents' individual perceptions.

Victoria is the second largest state in Australia, with a population of over 6 million people (ABS 2017a). The state is the most densely populated in the country, with the majority residents living in urban areas. Melbourne is the capital of Victoria and second-largest city in Australia, with a population of over 4.4 million living in approximately 500 neighbourhoods (ABS 2017b).

\section{Dependent variable}

This study seeks to test the extent to which perceived control is influenced by broader contextual factors of the neighbourhood. As a key dynamic in the theorisation of vulnerability, we argue that perceived control is of particular importance in understanding women's perceptions of risk and worry about crime (Killias 1990; Jackson 2009). Drawing on Jackson's (2009; 2011) research, we operationalise control through a scale of three items (all items are measured on a five-point Likert-type scale ranging from 1 $=$ "not at all able" to $5=$ "to a very great extent").

To what extent do you feel personally able to control whether or not you fall victim to each of the following crimes in the next twelve months?

- Having your home burgled

- Being robbed

- Being harassed

These items load on one factor and demonstrate strong reliability $(\alpha=0.93)$. Factor loadings range between 0.87 and 0.94 . Five percent of the variation in control was due to neighbourhood differences.

\section{Independent variables}

Correlations between neighbourhood level variables included in Table 1.

[insert Table 1] 
In line with neighbourhood effects scholarship on perceptions of crime, we include two broad characteristics of the neighbourhood that may influence control: concentrated disadvantage and collective efficacy.

Considering that an overall lack of resources at the neighbourhood-level may impact upon both women's and men's sense of control, we constructed a measure of concentrated disadvantage using total household income from the ABS 2016 census data. We employed the equivalised total household income to derive the proportion of residents in the suburb with household incomes in the bottom 30 percent of the median household income distribution for Victoria as a whole.

Neighbourhood collective efficacy captures the extent to which a community is able and willing to protect residents against crime. The following six items were employed in the neighbourhood survey to measure collective efficacy with all items measured on a 5-point Likert scale (1 strongly disagree and 5 strongly agree). Factor loadings ranged between 0.62 and 0.78 and all items loaded on one factor. The items formed a reliable scale $(\alpha=0.87)$ :

- This is a close-knit neighbourhood,

- People are here are willing to help their neighbours,

- People in this neighbourhood can be trusted,

- If any of the children or young people around here are causing trouble, local people will tell them off,

- If I sensed trouble while in this area, I could 'raise' attention from people who live here for help,

- The people who live here can be relied upon to call the police if someone is acting suspiciously.

In order to create a neighbourhood estimate of collective efficacy, we estimated fixed effects models that included indicator variables for all neighbourhoods in the Victorian sample and individual characteristics that might systematically bias perceptions of collective efficacy in the neighbourhood. ${ }^{2}$ We then used the estimated coefficients for each of the neighbourhoods from these analyses as unbiased estimates of the amount of collective efficacy at the neighbourhood level. ${ }^{34}$

Using administrative data from the Australian census and the Victoria Crime Statistics agency, we then constructed three separate variables to capture the gendered dynamics of the neighbourhood. We build on Jackson and colleagues (2017) work to identify those neighbourhood elements of gender stratification that may influence perceived control for women. These include differential economic

\footnotetext{
${ }^{2}$ These individual level demographics included age, marital status, dependent children, gender, language spoken at home, country of birth, educational attainment and residential mobility.

${ }^{3}$ A previous study found very many similarities whether constructing measures using a frequentist approach, as we do here in this article, or using a Bayesian approach (see Steenbeek and Hipp 2011, footnote 12 on page 846). ${ }^{4}$ This method is akin to that of Sampson, Raudenbush and Earls (1997) and Wickes and colleagues (2013).
} 
support for women across neighbourhood context (women's absolute access to resources), differential distribution of family labour duties between women and men (women's family labour) and women's victimisation rates in the neighbourhood. We describe each of these in turn below.

Following Jackson, Soller and Browning (2017), it is proposed that women's absolute accesses to neighbourhood socioeconomic resources shape women's perceptions of control. Differential economic support for women across neighbourhood context was measured through women's absolute access to resources, this was constructed from 2016 ABS Census Data.

To construct this measuring we use three items from the census to comprise women's absolute resource in the neighbourhood:

- The percentage of women who are employed,

- The percentage of women who are professional or managerial workers,

- The percentage of women who are ages 25 and older who are university graduates.

The validity of the scale was tested using principle component factor analyses. ${ }^{5}$ The analysis found the variables loaded on one factor for absolute resources and created a reliable scale $(\alpha 0.83)$, with factor loadings ranging from 0.73 to 0.98 . In the analyses, higher scores indicate neighbourhoods with higher concentration of women with access to economic resources.

Women's family labour is drawn from census data and is a single variable representing the percentage of single female led households. Previous scholarship has shown that while female social ties may provide protection against crime, there are significant constraints on female headed households which influence their ability to respond to crime problems (Rountree and Warner 1999). Female-headed households tend to cluster in suburbs with higher levels of socioeconomic disadvantage and indicate a disproportionate level of reliance on women for domestic labour (Wikström and Wikström 2001). Higher scores on this variable indicate greater concentration of female headed households.

Women's neighbourhood victimisation rates provide a measure of crime risk in the neighbourhood particular to women. Past research has shown neighbourhood crime rates have a direct relationship with fear (Brunton-Smith and Sturgis 2011; Barton et al. 2017). To create this variable, we use victim incident data from CSA to construct an incident rate per 100,000 females in the population averaged over three-years.

\section{Control variables}

Guided by social disorganisation theory and the neighbourhood effects scholarship, we also employ a number of neighbourhood-level control variables in our analyses. Data from the ABS 2016 census were employed to construct measures of neighbourhood diversity and residential mobility. A Blau index

\footnotetext{
${ }^{5}$ The results of the principle component factor analyses found significant concentration effects in the patterns of absolute resources. This contrasted from the findings of Jackson, Soller, and Browning (2017) who draw on relative resources, perhaps indicating differences in the neighbourhood context in Australia.
} 
captures linguistic diversity in order to capture neighbourhood heterogeneity, in line with previous studies of this nature within Australia (Wickes et al. 2013; Blau 1977). The Blau index indicates the probability of two randomly selected residents from the same suburbs speak a different language, the lower the number, the more homogeneous the area. Finally, residential mobility is measured using percentage of people in the suburb who have lived at the same address for the last five years.

As individual demographics and life experiences have an impact on vulnerability (Pain 2001), we control for a number of key demographic controls using XXXXXXX survey data. Age represented the age of the participant at the time of the survey and was recoded into six categories (see Table 2). Gender is a binary variable with males coded as (0) and females as $(1)^{6}$. Language other than English was also a binary variable with those who speak English coded as (0) and those who speak a language other than English coded as (1). Similarly marital status was coded as partner (0) and not partnered (1). There were three categories of educational attainment: 'high school or below' (1); 'trade, technical certificate or diploma' (2); 'university qualification' (3). Employment status was coded as: 'employed full time' (1); 'employed part time'(2); 'pensions/unemployed' (3) and 'not in the labour force'(4). ${ }^{7}$ Site consists of the categories 'urban Victoria'(0) and 'regional Victoria' (1). Prior victimisation was binary with 'no prior victimisation' coded as (0) and 'prior victimisation' coded as (1) (see Table 2).

[insert Table 2]

\section{Analysis}

To address our two research questions, we ran a series of multilevel mixed effects regression models to examine the relationship between the individual-level perception of control and the neighbourhoodlevel measures. This is conducted in two stages. Initially we estimated three main effects multilevel models, which build upon each other, to examine the theorised neighbourhood features that influence control. Model 1 examines the association between individual-level controls, neighbourhood-level controls, concentrated disadvantage and perceived control. Model 2 incorporates our measure of collective efficacy. In model 3, the gendered neighbourhood variables are added to examine the extent to which perceived control is driven by gender specific processes. ${ }^{8}$ In models 4 through 8 , we ran a series of cross-level interaction models to examine whether the relationship of our neighbourhood independent variables (women's absolute access to resources, women's family labour, women's neighbourhood victimisation rate, disadvantage and collective efficacy) has a differential effect on perceived control for women and men. We describe the results of these models below.

\footnotetext{
${ }^{6}$ Gender indicate the gender with which participants identified at the time of the survey.

${ }^{7}$ The latter category contains students.

${ }^{8}$ Concentrated disadvantage is not included in this model as it is too highly correlated with women's absolute resources (-0.77) and reliance on female family labor (0.71). This is to be expected given the women disproportionately effected by disadvantage. In this model we differentiate between overall disadvantage and specific gendered inequalities.
} 


\section{Results}

Model 1 examined the effects of the individual-level and neighbourhood-level control variables with concentrated disadvantage on perceptions of control. Results from this model found the strongest demographic predictors for perceived control over one's victimisation was gender, which remained significant across all three main effects models. Females reported significantly lower perceived control over their victimisation than their male counterparts $(\beta=-0.17, \mathrm{z}=-3.89, \mathrm{p}<.001)$. This aligns with the previous research on vulnerability, specifically that women's heightened worry about crime are in part due to the perception that they have lower control over their victimisation (Jackson 2009). Interestingly, other demographic factors previously employed as proxies for vulnerability, such as age and language spoken at home, were not significantly correlated with individuals perceived control. Educational attainment was significantly associated with perceived control. Those with a university degree perceived higher control than those with a high school qualification $(\beta=0.15, \mathrm{z}=2.74 \mathrm{p}<.01)$. Participants who lived in regional suburbs perceived higher control than those in urban suburbs $(\beta=$ $0.43, \mathrm{z}=3.29, \mathrm{p}<.001)$. Prior victimisation did not have a significant relationship to perceived control. This is of particular interest as previous research finds that individuals' worry about crime and perceived risk of victimisation is heightened for those with prior victimisation experience, however these experiences do not influence perceptions of control. Neither linguistic heterogeneity nor residential mobility influenced control. Higher levels of concentrated disadvantage were significantly associated with lower control suggesting that individuals who live in communities with fewer collective resources perceive less control over their victimisation $(\beta=-0.01, \mathrm{z}=-2.88, \mathrm{p}<.01)$.

Model 2 incorporates our second variable: collective efficacy. Surprisingly, collective efficacy was not significantly associated with perceived control $(\beta=0.17, \mathrm{z}=0.76)$. The inclusion of collective efficacy did not mediate the relationship between any of the neighbourhood variables and perceived control. At the individual level, females reported less control $(\beta=-0.17, \mathrm{z}=-3.89, \mathrm{p}<.001)$, and those with university qualifications $(\beta=0.14, z=3.71, p<.01)$ reported greater control. As was the case in model 1 , living in regional areas $(\beta=0.41, \mathrm{z}=3.15, \mathrm{p}<.01)$ was associated with greater control. Concentrated disadvantage remained the key neighbourhood indicator of control $(\beta=-0.01, z=-2.62, p<.01)$, yet the inclusion of collective efficacy slightly decreased the significance.

In model 3, we include the three variables that capture gendered neighbourhood dynamics: absolute resources for women, reliance on women for family labour and women's neighbourhood victimisation rate. These had no effect on perceived control (see Table 3). To assess whether the gendered dynamics of the neighbourhood was linked to women's perceived control, the analysis then examined three cross-level interaction models with each gendered neighbourhood variable and gender. Contrary to our expectations, these variables were not significantly associated with perceived control for women or men (see Table 4). 
The last step of the analysis evaluated whether general neighbourhood variables had a distinct impact on perceived control for women and men (see Table 4). First, we ran a model with cross-level interactions between gender and collective efficacy. While collective efficacy was not significant in earlier models, we find collective efficacy is important for women's perception of control (male $\beta=$ $0.18, \mathrm{z}=-0.75, \mathrm{p}=$ not significant; female $\beta=0.53,2.19, \mathrm{p}<.05$ ). The difference between women and men is pronounced for women living in areas with low collective efficacy. Our results show that in collectively efficacious communities, the neighbourhood does not drive differences between women's and men's perceived control, yet in communities with low collective efficacy, women's perceived control is significantly lower than men's (Figure 1).

\section{[Insert Table 4] \\ [Insert Figure 1]}

The final model examined the effects of concentrated disadvantage on women and men. In earlier models, concentrated disadvantage had a sustained correlation with lower levels of control. Cross-level interactions showed that concentrated disadvantage was particularly significant for women (male $\beta=-0.01, \mathrm{z}=-1.99, \mathrm{p}=0.05$; female $\beta=-0.01, \mathrm{z}=-3.18, \mathrm{p} .<001$ ). Figure 2 demonstrates there is a linear relationship between control and disadvantage for both women and men, and this relationship is stronger for women. Those who live in areas with less concentrated disadvantage perceived higher levels of control.

\section{[Insert Figure 2]}

\section{Discussion}

This paper examined perceived vulnerability to crime and the neighbourhood dynamics that shape differences in women's and men's reported sense of control over victimisation. In so doing, we build upon the work of Jackson and colleagues (2017) through analytical consideration of the gendered neighbourhood dynamics and how these interplay with women's and men's individual perceptions of control over victimisation. We hypothesised that three key neighbourhood features; higher absolute access to resources for women, lower reliance on women for family labour and lower neighbourhood victimisation rates for women would heighten women's perceived control over their victimisation.

Our analyses did not support this hypothesis. Jackson and colleagues (2017) demonstrated the importance of economic resources for perceptions of crime. Their study found that women who lived in neighbourhoods where women and men have similar levels of economic resources perceived lower social disorder, such as public displays of threatening behaviour, than those living in more unequal neighbourhoods. Our study indicates this process does not apply to women's perceived control over 
victimisation. Instead, women's sense of control was largely influenced by generalised neighbourhood conditions (disadvantage) and processes (collective efficacy).

The presence of disadvantage did have a differential influence on women's and men's perceptions of control over their victimisation. Our findings suggest that disadvantage is pernicious for women's and men's sense of control. It highlights the intersection of ecological vulnerability and individual vulnerability as this relationship is notably stronger for women than men. This says something particularly interesting about an individual's own vulnerability, such that vulnerability is not solely inherent to the person, but is influenced and reinforced through neighbourhood economic inequality. Cobbina and colleagues (2008) asserted disadvantaged neighbourhoods created a unique ecological context for women, in which their communities were male dominated and instances of male violence were more common. Furthermore, Kern's (2005: 357) examination of women's safety in Toronto demonstrates affluent women are able to "appropriate and claim urban space in a number of ways" through highlighting the salience of economic privilege. It would appear concentrations of economic privilege protects all residents living in a community, while concentrations of economic disadvantage can be harmful as they create a context in which residents perceive themselves as unable to control potential victimisation.

Looking to the relationship between control and collective efficacy, our findings provide additional support that these general neighbourhood processes matter more for women than men (Brunton-Smith and Sturgis 2011). Collective efficacy captures the capacity of the community to exert informal social control and solve neighbourhood problems. While there is a large body of evidence that collective efficacy can protect against crime (Mazerolle, Wickes and McBroom 2010; Sampson, Raudenbush and Earls 1997; Wikström et al. 2012), we did not find that it led to a greater sense of control in the main effects analysis. However, in our interaction models, we did find that collective efficacy was particularly important for women. Our findings suggest women's perceptions of control over potential victimisation is informed through the actions and behaviours of all residents, including their male counterparts, in the neighbourhood to protect against crime, rather than women having access to resources to protect themselves. Wickes, Broidy and Hipp (2018) found men in the neighbourhood were more likely to exercise informal social control actions in response to crime and community problems. Given women's perceptions of crime are largely understood through male predatory behaviour and violence (Stanko 1990), it may be that the social dynamics that create collectively efficacious neighbourhoods reduce male violence and increase positive male behaviours in the neighbourhood which engender a sense of control over potential victimisation for women.

There were other findings of note in this study. Of most interest, those living in regional areas exhibited higher levels of perceived control for women and men. Previous scholarship has largely focused on perceptions of safety and vulnerability in urban communities. Few studies have examined the difference between urban and regional perceptions of crime (Pleggenkuhle and Schafer 2018). Pleggenkuhle and Scafer (2018) study found social trust is important for fear in regional communities 
particularly for female participants. Regional communities have smaller populations and less residential mobility, which may create a unique set of attitudes and behaviours in regional areas leading to a perception of greater control compared to those living in urban areas. In contrast, Hogg and Carrington's (2003) examination of violence in regional communities revealed the prevalence of often hidden gendered violence in some rural areas. The authors assert "bonds conceal, rather than reveal" critiquing the assumption strong community ties in regional areas leads to less violence (Hogg and Carrington 2003: 293). It may be plausible our findings indicate regional communities create contexts in which people are less likely to divulge their lower perceptions of control, or rather that the close knit nature of such communities and the specific nature of more familial gendered violence, might result in different conceptualisations of control. Future research should consider these divergent social contexts for women.

Despite the advances made in this paper, there are limitations to note. Previous research has shown that women do not exaggerate their fear of crime, but instead, men may suppress their concerns about safety (Sutton and Farrall 2004; Pain 2001). It is possible the variation of women's and men's reported control is in part due to respondent's expressing expected norms around gender roles. Given the significant difference between women's and men's perceived control, future research should consider the way in which socialisation of gender roles influence how residents think about their own control and how this is influenced by the neighbourhood.

\section{Conclusion}

Women derive their sense of control in part from the condition and features of environment in which they live. This paper has examined the ecological drivers of perceived control over potential victimisation highlighting the differential effects of neighbourhood poverty and collective efficacy on women's perceived vulnerability. Findings indicate that it is not the gendered dynamics of the neighbourhoods which influence women's perceived control rather generalised social processes, collective efficacy, and broad experiences of neighbourhood disadvantage that matter for women. These understandings of the neighbourhood context for individual control are important when considering the dynamics that create and reinforces women's vulnerability.

\section{Funding}

This work was supported by the Victorian Department of Justice and Community Safety, Australia. 


\section{Reference list}

Australian Bureau of Statistics. (2017a), 2071.0 - Census of Population and Housing: Reflecting Australia - Stories from the Census, 2016. Australian Bureau of Statistics, July 2017 [https://www.abs.gov.au/ausstats/abs@.nsf/Lookup/by\%20Subject/2071.0 2016 Main\%20Fea tures Cultural\%20Diversity\%20Data\%20Summary 30]

Australian Bureau of Statistics. (2017b), 2016 Census Community Profiles - Greater Melbourne. $\begin{array}{lllll}\text { Australian } & \text { Bureau } & \text { of } & \text { Statistics, } & \text { October }\end{array}$ [https://quickstats.censusdata.abs.gov.au/census_services/getproduct/census/2016/communitypr ofile/2GMEL?opendocument]

Barton, M., Frederick W., Melinda J., and Hickey, D. (2017). 'An Investigation of the Influence of the Spatial Distribution of Neighborhood Violent Crime on Fear of Crime.' Crime \& Delinquency, 63 (13): 1757-76. https://doi.org/10.1177/0011128716671874.

Baxter, J., Hewitt, B., and Western, M. (2005), 'Post-familial families and the domestic division of labour.' Journal of Comparative Family Studies, 36(4):583-600.

Blau, P. (1977), 'A Macrosociological Theory of Social Structure.' American Journal of Sociology, 83 (1): $26-54$.

Blumberg, R. (1984), 'A General Theory of Gender Stratification.' Sociological Theory, 2: 23. https://doi.org/10.2307/223343.

Brunton-Smith, I., and Sturgis, P. (2011), 'Do Neighborhoods Generate Fear of Crime? An Empirical Test Using the British Crime Survey.' Criminology, 49 (2): 331-69. https://doi.org/10.1111/j.1745-9125.2011.00228.x.

Brunton-Smith, I., Jackson, J., and Sutherland, A. (2014), 'Bridging Structure and Perception: On the Neighbourhood Ecology of Beliefs and Worries About Violent Crime.' British Journal of Criminology, 54 (4): 503-26. https://doi.org/10.1093/bjc/azu020.

Cobbina, J., Miller, J. and Brunson, R. (2008), 'Gender, Neighborhood Danger, and Risk-avoidance Strategies Among Urban African-American Youths.' Criminology, 46 (3): 673-709. https://doi.org/10.1111/j.1745-9125.2008.00122.x.

Farrall, S., Jackson, J. and Gray, E. (2009), Social Order and the Fear of Crime in Contemporary Times. Oxford University Press. https://doi.org/10.1093/acprof:oso/9780199540815.001.0001.

Ferraro, K. (1996), ‘Women's Fear of Victimization: Shadow of Sexual Assault?' Social Forces, 75 (2): 667-90.

Fileborn, B. (2019), 'Naming the Unspeakable Harm of Street Harassment: A Survey-Based Examination of Disclosure Practices', Violence Against Women, 25(2): 223-248.

Fisher, B. S., and Nasar, J. L. (1992), 'Fear of crime in relation to three exterior site features prospect, refuge and escape.' Environment and Behavior, 24(1): 214-239. 
Fisher, B. S., and Nasar, J. L. (1995), 'Fear spots in relation to microlevel physical cues: exploring the overlooked.' Journal of Research in Crime and Delinquency, 32(2): 214-239.

Fisher, B., and May, D. (2009), 'College Students' Crime-Related Fears on Campus: Are FearProvoking Cues Gendered?' Journal of Contemporary Criminal Justice, 25 (3): 300-321. https://doi.org/10.1177/1043986209335013.

Franklin, C., and Franklin, T. (2009), 'Predicting Fear of Crime: Considering Differences Across Gender.' Feminist Criminology, 4 (1): 83-106. https://doi.org/10.1177/1557085108325196.

Greenbaum, S.D., and Greenbaum, P.E. (1985), 'The ecology of social networks in four urban neighborhoods.' Social networks, 7(1), pp.47-76.

Hale, C. (1996), 'Fear of Crime: A Review of the Literature.' International Review of Victimology, 4 (2): 79-150. https://doi.org/10.1177/026975809600400201.

Hirtenlehner, H. and Farrall, S. (2014). 'Is the 'Shadow of Sexual Assault' Responsible for Women's Higher Fear of Burglary?' British Journal of Criminology, 54 (6): 1167-85. https://doi.org/10.1093/bjc/azu054.

Hogg, R., and Carrington, K. (2003), 'Violence, spatiality and other rurals.' Australian \& New Zealand Journal of Criminology, 36(3):293-319.

Jackson, A. (2016), 'The Combined Effect of Women's Neighborhood Resources and Collective Efficacy on IPV: Women's Resources and Collective Efficacy on IPV.' Journal of Marriage and Family, 78 (4): 890-907. https://doi.org/10.1111/jomf.12294.

Jackson, A., Soller, B., and Browning, C. (2017), 'The Influence of Women's Neighborhood Resources on Perceptions of Social Disorder: Influence of Women's Neighborhood Resources on Perceptions of Social Disorder.' City and Community, 16 (2): 189-208. https://doi.org/10.1111/cico.12229.

Jackson, J. (2009), 'A Psychological Perspective on Vulnerability in the Fear of Crime.' Psychology, Crime and Law, 15 (4): 365-90. https://doi.org/10.1080/10683160802275797.

Jackson, J. (2011), 'Revisiting Risk Sensitivity in the Fear of Crime.' Journal of Research in Crime and Delinquency, 48 (4): 513-37. https://doi.org/10.1177/0022427810395146.

Kern, L. (2005), 'In place and at home in the city: Connecting privilege, safety and belonging for women in Toronto.' Gender, Place and Culture, 12(3): 357-377.

Killias, M., and Clerici, C. (2000), 'Different measures of vulnerability in their relation to different dimensions of fear of crime.' British Journal of Criminology, 40(3): 437-450.

Killias, M. (1990), 'Vulnerability: Towards a Better Understanding of a Key Variable in the Genesis of Fear of Crime.' Violence and Victims, 5 (2): 97-108. https://doi.org/10.1891/0886-6708.5.2.97.

Koskela, H. (1997), “Bold Walk and Breakings': Women's Spatial Confidence versus Fear of Violence.' Gender, Place and Culture, 4 (3): 301-20. https://doi.org/10.1080/09663699725369.

Lee, M. (2007) Inventing Fear of Crime: Criminology and the politics of anxiety, Willan, Collumpton. 
May, D. C. (2001), 'The Effect of Fear of Sexual Victimization on Adolescent Fear of Crime.' Sociological Spectrum, 21 (2): 141-74. https://doi.org/10.1080/02732170119080.

Mazerolle, L.,Wickes, R. and McBroom, J. (2010), 'Community Variations in Violence: The Role of Social Ties and Collective Efficacy in Comparative Context.' Journal of Research in Crime and Delinquency, 47 (1): 3-30. https://doi.org/10.1177/0022427809348898.

Miller, J. (2008), Getting Played. New York: New York University Press.

Pain, R. (1997), 'Whither Women's Fear? Perceptions of Sexual Violence in Public and Private Space.' $\begin{array}{lllllll}\text { International } & \text { Review } & \text { of } & \text { Victimology, } & 4 & \text { (4): } & \text { 297-312. }\end{array}$ https://doi.org/10.1177/026975809700400404.

Pain, R. (2000), 'Place, Social Relations and the Fear of Crime: A Review.' Progress in Human Geography, 24 (3): 365-87. https://doi.org/10.1191/030913200701540474.

Pain, R. (2001), 'Gender, Race, Age and Fear in the City.' Urban Studies, 38 (5-6): 899-913. https://doi.org/10.1080/00420980120046590.

Pantazis, C. (2000), '“Fear of Crime', Vulnerability and Poverty.' British Journal of Criminology, 40 (3): 414-36. https://doi.org/10.1093/bjc/40.3.414.

Pleggenkuhle, B., and Schafer, J. (2018), 'Fear of Crime among Residents of Rural Counties: An Analysis by Gender.' Journal of Crime and Justice, 41 (4): 382-97. https://doi.org/10.1080/0735648X.2017.1391109.

Raudenbush, S. and Sampson, R. (1999), 'Ecometrics: toward a science of assessing ecological settings, with application to the systematic social observation of neighborhoods.' Sociological methodology, 29(1), 1-41.

Reid, L. and Konrad, M. (2004), 'The Gender Gap in Fear: Assessing the Interactive Effects of Gender and Perceived Risk on Fear of Crime.' Sociological Spectrum, 24 (4): 399-425. https://doi.org/10.1080/02732170490431331.

Riggs, S, and Cook, C. (2015), 'The Shadow of Physical Harm? Examining the Unique and Gendered Relationship Between Fear of Murder Versus Fear of Sexual Assault on Fear of Violent Crime.' $\begin{array}{llllll}\text { Journal of } & \text { Interpersonal } & \text { Violence, } & 30 & \text { (14): } & 2383-2409 .\end{array}$ https://doi.org/10.1177/0886260514553117.

Rountree, P., and Warner, B. (1999), 'Social Ties and Crime: Is the Relationship Gendered?.' Criminology, 37 (4): 789-814. https://doi.org/10.1111/j.1745-9125.1999.tb00505.x.

Sampson, R. J., Raudenbush, S., and Earls, F. (1997), 'Neighborhoods and Violent Crime: A Multilevel Study of Collective Efficacy.' $\quad \underline{\text { Science, }} 277 \quad$ (5328): 918-24. https://doi.org/10.1126/science.277.5328.918.

De Beauvoir, S. (1949). The Second Sex, trans. and ed. HM Parshley ([1952].

Snedker, K. (2012), 'Explaining the Gender Gap in Fear of Crime: Assessments of Risk and Vulnerability Among New York City Residents.' Feminist Criminology, 7 (2): 75-111. https://doi.org/10.1177/1557085111424405. 
Snedker, K. (2015), 'Neighborhood Conditions and Fear of Crime: A Reconsideration of Sex Differences.' Crime and Delinquency, 61 (1): 45-70. https://doi.org/10.1177/0011128710389587.

Soller, B., and Jackson, A. L. (2018), 'Girls' Self-Efficacy in the Context of Neighborhood Gender Stratification.' Social Science Research, 72 (May): 100-114. https://doi.org/10.1016/j.ssresearch.2018.01.005.

Stanko, E. (1990), Everyday Violence: How Women and Men Experience Sexual and Physical Danger. The University of Virginia: Pandora.

Stanko, E. (1995), 'Women, Crime, and Fear.' The ANNALS of the American Academy of Political and Social Science, 539 (1): 46-58. https://doi.org/10.1177/0002716295539001004.

Stanko, E. (1997), 'Safety Talk, Conceptualising Women's Risk Assessment as a Technology of the Soul.' Theoretical Criminology, 1 (4): 479-449.

Steenbeek, W. and Hipp, J.R. (2011), 'A Longitudinal Test of Social Disorganization Theory: Feedback Effects Among Cohesion, Social Control, and Disorder.' Criminology, 49: 833-871. https://doi.org/10.1111/j.1745-9125.2011.00241.x

Sutton, R. and Farrall, S. (2004), 'Gender, Socially Desirable Responding and the Fear of Crime: Are Women Really More Anxious about Crime?' British Journal of Criminology, 45 (2): 212-24. https://doi.org/10.1093/bjc/azh084.

Tulloch, M. (2003), 'Combining Classificatory and Discursive Methods: Consistency and Variability in Responses to the Threat of Crime.' British Journal of Social Psychology, 42 (3): 461-76. https://doi.org/10.1348/014466603322438260.

Tulloch, M., and Jennett, C. (2001), 'Women's Responses to Fear of Crime.' Security Journal, 14 (2): 53-62. https://doi.org/10.1057/palgrave.sj.8340082.

Walklate, S. (2017), 'Gender, Violence and the Fear of Crime Women as Fearing Subjects?' In M. Lee \& G. Mythen The Routledge International Handbook on Fear of Crime, Routledge, 14-28.

Walklate, S. (1997), 'Risk and Criminal Victimization: A Modernist Dilemma?' British Journal of Criminology, 37 (1): 35-45. https://doi.org/10.1093/oxfordjournals.bjc.a014148.

Warr, M. (1984), 'Fear of Victimization: Why Are Women and the Elderly More Afraid?' Social Science Quarterly, 65 (3): 23.

Warr, M. (1987), 'Fear of Victimization and Sensitivity to Risk.' Journal of Quantitative Criminology, 3 (1): 29-46. https://doi.org/10.1007/BF01065199.

Wickes, R., Broidy, L., and Hipp, J. R. (2018). 'Responding to Neighborhood Problems: Is the Division of Community Labor Gendered?' Crime and Delinquency, 64 (9): 1215-41. https://doi.org/10.1177/0011128717750390.

Wickes, R., Hipp, J., Zahnow, R. and Mazerolle, L. (2013). "Seeing’ Minorities and Perceptions of Disorder: Explicating the Mediating and Moderating Mechanisms of Social Cohesion: Minorities 
and Perceptions of Disorder.' Criminology, 51 (3): 519-60. https://doi.org/10.1111/17459125.12011.

Wikström, S, and Wikström, P. (2001), 'Why Are Single Parents More Often Threatened with Violence? A Question of Ecological Vulnerability?' International Review of Victimology, 8 (2): 183-98. https://doi.org/10.1177/026975800100800205.

Wikström, P., Oberwittler, D., Treiber, K., and Hardie, B. (2012), Breaking rules: the social and situational dynamics of young people's urban crime. Oxford University Press, Oxford 


\section{Tables and figures}

Table 1 Correlation between Neighbourhood cluster-level variables

\begin{tabular}{|l|l|l|l|l|l|l|l|}
\hline \multicolumn{2}{|l|}{ Neighbourhood variables (n=80) } & 1 & 2 & 3 & 4 & 5 & 6 \\
\hline 1 & Residential mobility & & & & & & \\
\hline 2 & Linguistic heterogeneity & 0.29 & & & & & \\
\hline 3 & Concentrated low income & 0.18 & -0.07 & & & & \\
\hline 4 & Latent collective efficacy & 0.29 & 0.46 & -0.15 & & & \\
\hline 5 & Absolute access to resources for women & -0.38 & -0.12 & -0.77 & 0.02 & & \\
\hline 6 & Absolute single parent households & 0.06 & -0.20 & 0.71 & -0.24 & -0.62 & \\
\hline 7 & Absolute victimisation & -0.37 & -0.13 & 0.17 & -0.28 & -0.04 & 0.12 \\
\hline
\end{tabular}

Table 2 Summary statistics for all variables

\begin{tabular}{|c|c|c|c|c|}
\hline Variables & $\% /$ Mean & SD & Min & $\operatorname{Max}$ \\
\hline Perceptions of control & 2.71 & 1.05 & 1 & 5 \\
\hline \multicolumn{5}{|l|}{ Age } \\
\hline $15-19$ years & 3.09 & & & \\
\hline $20-34$ years & 17.71 & & & \\
\hline $35-44$ years & 20.8 & & & \\
\hline 45 - 59 years & 26.9 & & & \\
\hline $60-74$ years & 22.76 & & & \\
\hline 75 years and over & 8.73 & & & \\
\hline \multicolumn{5}{|l|}{ Gender } \\
\hline Male & 50.91 & & & \\
\hline Female & 49.09 & & & \\
\hline \multicolumn{5}{|l|}{ Language spoken at home } \\
\hline English & 76.55 & & & \\
\hline Language other than English & 23.45 & & & \\
\hline \multicolumn{5}{|l|}{ Marital status } \\
\hline Not currently partnered & 30.58 & & & \\
\hline Partner & 69.42 & & & \\
\hline \multicolumn{5}{|l|}{ Country of birth } \\
\hline Australia & 72.25 & & & \\
\hline Overseas & 27.75 & & & \\
\hline \multicolumn{5}{|l|}{ Educational attainment } \\
\hline High school & 29.75 & & & \\
\hline Trade certificate or diploma & 21.31 & & & \\
\hline University qualification & 48.94 & & & \\
\hline \multicolumn{5}{|l|}{ Employment } \\
\hline Full time employed & 47.47 & & & \\
\hline Part time employed & 15.14 & & & \\
\hline On a pension/Self funded retiree/self supporting & 25.86 & & & \\
\hline Not in the labour force/ Student/ Unemployed & 11.53 & & & \\
\hline
\end{tabular}




\begin{tabular}{|l|l|l|l|l|}
\hline Locality & & & & \\
\hline Urban & 87.21 & & & \\
\hline Regional & 12.79 & & & \\
\hline Victimisation history & & & & \\
\hline Not previously a victim & 87.81 & & & \\
\hline Previously a victim of crime & 12.19 & & & 49.72 \\
\hline Absolute access to resources for women & 30.50 & 8.49 & 12.88 & 12.16 \\
\hline Absolute single parent households & 6.01 & 1.91 & 1.20 & 8764.94 \\
\hline Absolute victimisation & 2767.62 & 1429.47 & 2 & -0.68 \\
\hline Latent collective efficacy & -0.12 & 0.18 & 0.17 & 0.88 \\
\hline Linguistic heterogeneity & 0.58 & 0.20 & 12.91 & 51.64 \\
\hline Concentrated low income & 24.85 & 8.04 & 25.69 & 73.80 \\
\hline Residential mobility & 53.11 & 9.24 & \\
\hline
\end{tabular}


Table 3 Dependent variable perceived control models 1-3

\begin{tabular}{|c|c|c|c|c|c|c|c|c|c|}
\hline & \multicolumn{3}{|l|}{ Model 1} & \multicolumn{3}{|l|}{ Model 2} & \multicolumn{3}{|l|}{ Model 3} \\
\hline & $\beta$ & $\mathrm{z}$ & $\mathrm{SE}$ & $\beta$ & $\mathrm{z}$ & $\mathrm{SE}$ & $\beta$ & $\mathrm{z}$ & $\mathrm{SE}$ \\
\hline \multicolumn{10}{|l|}{ Age (ref: 15 - 19 years) } \\
\hline $20-34$ years & -0.20 & -1.51 & 0.13 & -0.19 & -1.48 & 0.13 & -0.19 & -1.48 & 0.13 \\
\hline $35-44$ years & -0.19 & -1.43 & 0.13 & -0.19 & -1.40 & 0.13 & -0.19 & -1.39 & 0.13 \\
\hline $45-59$ years & -0.15 & -1.16 & 0.13 & -0.15 & -1.14 & 0.13 & -0.15 & -1.12 & 0.13 \\
\hline $60-74$ years & -0.22 & -1.54 & 0.14 & -0.21 & -1.52 & 0.14 & -0.21 & -1.49 & 0.14 \\
\hline 75 years and over & -0.24 & -1.55 & 0.16 & -0.24 & -1.53 & 0.16 & -0.24 & -1.51 & 0.16 \\
\hline \multicolumn{10}{|l|}{ Gender } \\
\hline Female & $-0.17 * * *$ & -3.89 & 0.04 & $-0.17 * * *$ & -3.89 & 0.04 & $-0.17 * * *$ & -3.88 & 0.04 \\
\hline \multicolumn{10}{|l|}{ Language spoken at home } \\
\hline Language other than English & -0.06 & -1.08 & 0.05 & -0.06 & -1.07 & 0.05 & -0.06 & -1.12 & 0.05 \\
\hline \multicolumn{10}{|l|}{ Marital status (ref: Not currently partnered) } \\
\hline Partner & -0.07 & -1.45 & 0.05 & -0.07 & -1.46 & 0.05 & -0.07 & -1.45 & 0.05 \\
\hline \multicolumn{10}{|l|}{ Educational attainment (ref: High school) } \\
\hline Trade certificate or diploma & 0.09 & 1.57 & 0.06 & 0.09 & 1.56 & 0.06 & 0.09 & 1.56 & 0.06 \\
\hline University qualification & $0.15^{* *}$ & 2.74 & 0.05 & $0.14 * *$ & 2.71 & 0.05 & $0.15 * *$ & 2.80 & 0.05 \\
\hline \multicolumn{10}{|l|}{ Employment (ref: Full time employed) } \\
\hline Part time employed & 0.10 & 1.57 & 0.06 & 0.10 & 1.58 & 0.06 & 0.10 & 1.61 & 0.06 \\
\hline Self funded retiree/self supporting/ On a pension & 0.03 & 0.39 & 0.08 & 0.03 & 0.37 & 0.08 & 0.03 & 0.33 & 0.08 \\
\hline Not in the labour force/ Student/ Unemployed & -0.02 & -0.24 & 0.07 & -0.02 & -0.25 & 0.07 & -0.02 & -0.26 & 0.07 \\
\hline \multicolumn{10}{|l|}{ Locality (ref: urban) } \\
\hline Regional & $0.43 * * *$ & 3.29 & 0.13 & $0.41 * *$ & 3.15 & 0.13 & 0.24 & 1.91 & 0.12 \\
\hline \multicolumn{10}{|l|}{ Victimisation history } \\
\hline Previously a victim of crime & -0.02 & -0.29 & 0.06 & -0.02 & -0.29 & 0.06 & -0.02 & -0.27 & 0.06 \\
\hline Residential mobility & -0.01 & -1.41 & 0.00 & -0.01 & -1.56 & 0.00 & -0.01 & -1.83 & 0.00 \\
\hline Linguistic heterogeneity & 0.05 & 0.23 & 0.22 & 0.00 & 0.01 & 0.23 & 0.11 & 0.45 & 0.23 \\
\hline
\end{tabular}




\begin{tabular}{|c|c|c|c|c|c|c|c|c|c|}
\hline Concentrated low income & $-0.01 * *$ & -2.88 & 0.01 & $-0.01 * *$ & -2.62 & 0.01 & & & \\
\hline Latent collective efficacy & & & & 0.17 & 0.76 & 0.22 & 0.24 & 1.06 & 0.23 \\
\hline Absolute access to resources for women & & & & & & & 0.00 & -0.08 & 0.01 \\
\hline Absolute single parent households & & & & & & & -0.03 & -1.26 & 0.02 \\
\hline Absolute victimisation & & & & & & & 0.00 & -0.16 & 0.00 \\
\hline $\mathbf{N}$ & \multicolumn{3}{|l|}{$2580(80)$} & \multicolumn{3}{|c|}{$2580(80)$} & \multicolumn{3}{|c|}{$2580(80)$} \\
\hline Log likelihood & \multicolumn{3}{|l|}{-3729.06} & \multicolumn{3}{|l|}{-3728.77} & \multicolumn{3}{|c|}{-3730.83} \\
\hline $\mathrm{Chi}^{2}$ & \multicolumn{3}{|l|}{53.88} & \multicolumn{3}{|l|}{54.52} & \multicolumn{3}{|l|}{49.40} \\
\hline Intra Class Correlation (ICC) & \multicolumn{3}{|l|}{0.05} & \multicolumn{3}{|l|}{0.05} & \multicolumn{3}{|l|}{0.06} \\
\hline
\end{tabular}


Table 4 Dependent variable perceived control: cross-level interactions gender and neighbourhood conditions

\begin{tabular}{|c|c|c|c|}
\hline & $\beta$ & $\mathrm{Z}$ & $\mathrm{SE}$ \\
\hline \multicolumn{4}{|c|}{ Gender specific interactions } \\
\hline \multicolumn{4}{|l|}{ Absolute resources } \\
\hline Male & 0.00 & 0.29 & 0.01 \\
\hline Female & -0.00 & -0.44 & 0.01 \\
\hline \multicolumn{4}{|c|}{ Absolute family labour } \\
\hline Male & -0.02 & -0.75 & 0.02 \\
\hline Female & -0.04 & -1.77 & 0.03 \\
\hline \multicolumn{4}{|l|}{ Female victimisation } \\
\hline Male & 0.00 & 0.85 & 0.00 \\
\hline Female & -0.00 & -1.23 & 0.00 \\
\hline \multicolumn{4}{|c|}{ General neighbourhood interactions } \\
\hline \multicolumn{4}{|l|}{ Collective efficacy } \\
\hline Male & -0.18 & -0.75 & 0.24 \\
\hline Female & $0.53 *$ & 2.19 & 0.24 \\
\hline \multicolumn{4}{|c|}{ Concentrated low income } \\
\hline Male & $-0.01 *$ & -1.99 & 0.01 \\
\hline Female & $-0.02 * * *$ & -3.18 & 0.01 \\
\hline
\end{tabular}




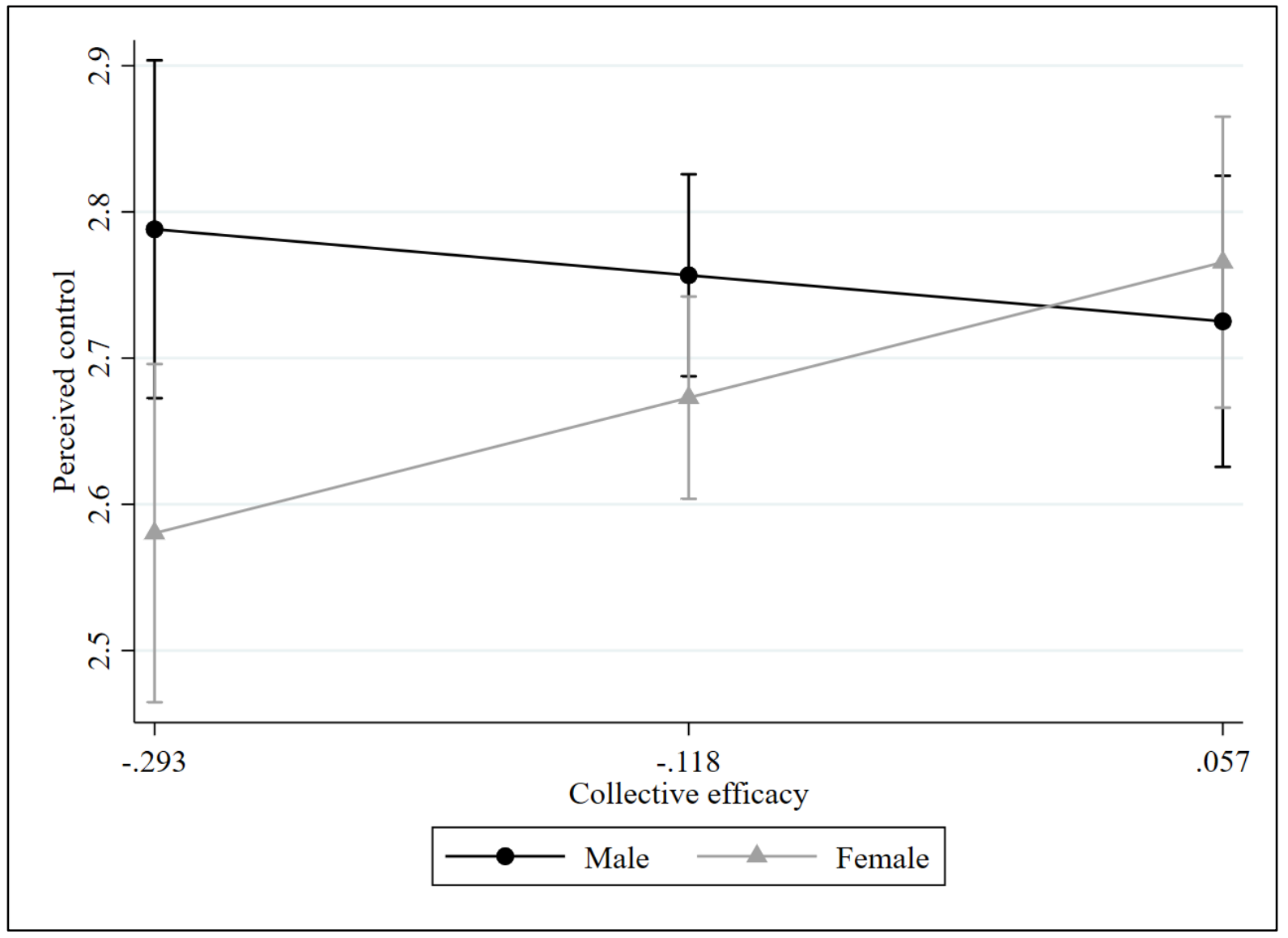

Figure 1 Collective efficacy and gender 


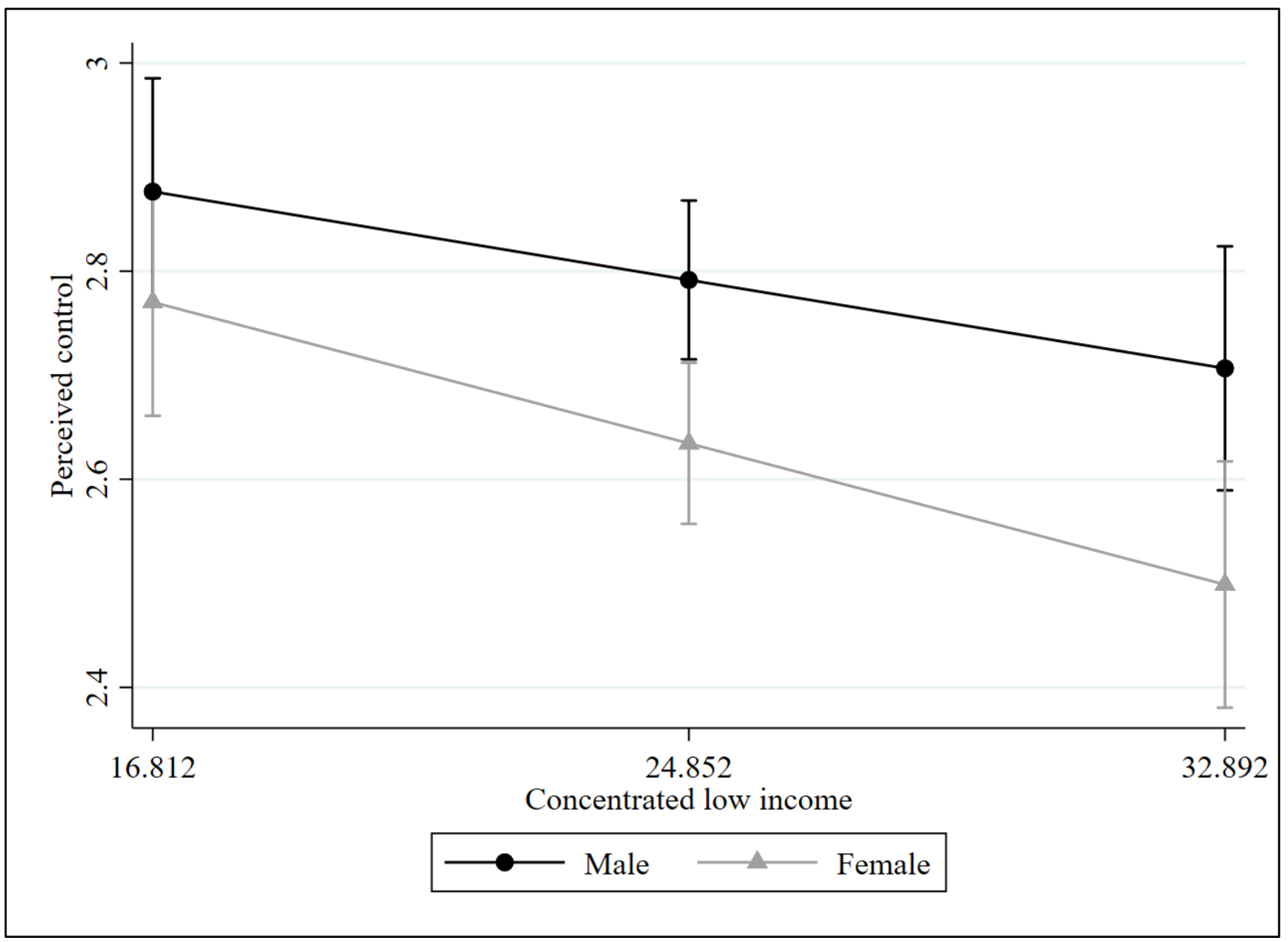

Figure 2 Concentrated disadvantage and gender 